\title{
WSN-BASED MONITORING SYSTEMS FOR THE SOLAR POWER STATIONS OF TELECOMMUNICATION DEVICES
}

\author{
KhuJAMATOV KHALIMJON ERGASHEVICH ${ }^{1}$, KhaSANOV DOSTON \\ TURAYEVICH $^{1 *}$, FAYZULLAEV BAYRAM ARTIKBAYEVICH ${ }^{2}$ \\ AND REYPNAZAROV ERNAZAR NURJAMIYEVICH ${ }^{1}$ \\ ${ }^{1}$ Department of "Data Communication Networks and Systems" of TUIT named after \\ Muhammad al-Khwarizmi, 100200 Tashkent, Uzbekistan. \\ ${ }^{2}$ Department of "Telecommunication engineering" of Nukus Branch of TUIT named after \\ Muhammad al-Khwarizmi, Nukus, Karakalpakstan \\ *Corresponding author: dhasanov0992@gmail.com
}

(Received: 27th April 2020; Accepted: $11^{\text {th }}$ November 2020; Published on-line: $4^{\text {th }}$ July 2021)

\begin{abstract}
Renewable energy sources are an increasingly popular way to generate electrical energy for telecommunications systems. The use and effectiveness of remote monitoring systems has led to growing interest relative to telecommunications systems. As with any new technology, new problems have arisen in using renewable energy sources in telecommunications systems and the use of IoT-based remote monitoring systems in them. In particular, one of these problems is the decentralization of remote monitoring systems for renewable power plants for telecommunication systems. The paper details the stages of development and modelling of open-source centralized monitoring systems for solar power stations for telecommunication systems. In this paper, a real-time remote monitoring system for solar power sources was modelled and investigated by wireless sensor networks for telecommunications devices. Proteus software environment was obtained for modelling. Before modelling the system, a system structure and a block diagram were developed, where each of the elements that are part of the system are described. Software for the system was created. The designed structure and software were tested by modelling. The results of the modelling were presented in a virtual terminal, an oscillography, and a local web browser.
\end{abstract}

ABSTRAK: Sumber tenaga boleh baharu semakin meningkat popular dalam menghasilkan tenaga elektrik bagi sistem telekomunikasi. Penggunaan dan keberkesanan sistem pemonitoran jarak jauh dalam jaringan ini telah membawa kepada peningkatan minat kepada tenaga boleh baharu. Walau bagaimanapun, melalui sistem teknologi baru ini, masalah baru timbul dalam penggunaan punca tenaga boleh baharu dalam sistem telekomunikasi dan penggunaan bersama sistem pemonitoran berdasarkan IoT. Khususnya dalam desentralisasi sistem pemonitoran jarak jauh bagi loji kuasa sistem telekomunikasi. Kajian ini merincikan peringkat pembinaan dan model sumber terbuka berpusat sistem pemonitoran bagi sistem janakuasa solar sistem telekomunikasi. Kajian ini turut memodelkan sistem pemonitoran jarak jauh secara langsung bagi sumber kuasa solar dan dikaji dengan rangkaian sensor tanpa jaringan bagi alatan telekomunikasi. Perisian Proteus telah dihasilkan bagi model ini. Sebelum model sistem dibina, struktur sistem dan gambar rajah blok dibina. Setiap unsur dalam sistem ini diperihalkan. Perisian bagi sistem ini turut dibina. Struktur yang dibina dan perisian ini diuji melalui model. Hasil dapatan model dibentangkan dalam pangkalan maya, oscilograf dan pelayar web tempatan. 
KEYWORDS: real-time monitoring system; solar power stations; IoT; WSN; ZigBee; Proteus software

\section{INTRODUCTION}

Presently, Smart Grids - smart energy systems based on IoT - are used to provide a stable and high-quality power supply to telecommunication facilities. This leads to solving many problems, including remote monitoring, two-way information systems, energy consumption controls, increasing energy demands, and providing reliability and security $[1,2]$.

Real-time remote monitoring of solar power sources for Telecommunication devices through IoT based on wireless sensor networks are the basis of Smart Grid systems [1], [2]. Real-time remote monitoring of these solar power sources requires remote monitoring of solar panel voltage, current, light illumination, dusting, environment and battery temperature, battery current, battery voltage, as well as other types of measurements of telecommunication devices.

In traditional remote monitoring of solar power sources based on IoT, the controller devices unit (CDU) receives relevant data from each sensor (how it is used in real-time, in hours, in days, in weeks, etc.) [3]. The resulting data is transferred to the database (DB) and will be provided to personnel by mobile communication via the Arduino Ethernet module or Arduino GSM module, and viewed as SMS, web pages, and other forms (Fig.1) [4], [1].

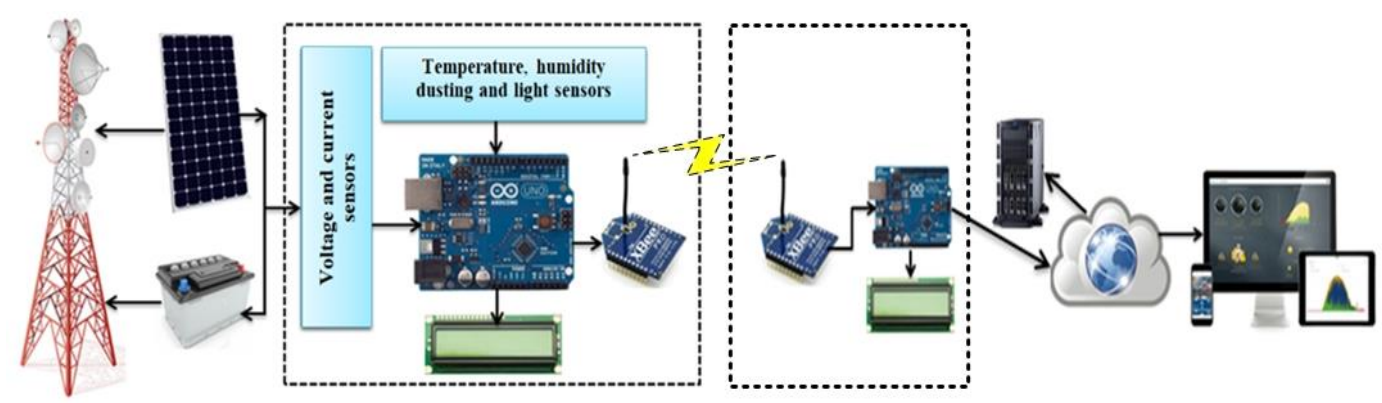

Fig. 1: Scheme of construction of monitoring system of the solar power station for telecommunication devices.

The collected data about the operating mode in the monitoring will be sent to the monitoring center, where the responsible personnel can promptly make a decision to correct the situation. Operational and maintenance personnel will be able to quickly identify and fix the cause of the malfunction based on detailed information from a set of technical tools installed in the monitoring system [2]. In this regard, by reducing the cost of recovery and downtime during preventive maintenance, the use of monitoring systems will increase the reliability of telecommunications systems, which can be evaluated with the coefficient of technical maintenance.

A positive economic effect is achieved with the use of monitoring systems, many actions aimed at checking the technical condition, at maintaining the system's performance, and at identifying the causes of malfunctions are performed remotely automated or automatically [5-6]. 


\section{LITERATURE REVIEW}

Several leading scientists have researched remote monitoring of energy supply sources, including remote monitoring of solar power plants, and the use of wireless sensor networks in remote monitoring systems. We have analyzed some of these studies that are relevant to the research topic.

In 2012, Chunming et al. [4] described the monitoring system for wind power generation based on a wireless sensor network. Aimed at meeting the demands of a wind power generation monitoring system, this thesis describes a system that builds up a wireless, real-time, multi-object, distant monitoring system for wind power generation.

In 2014, Nagalakshmi et al. [7] described the design and development of a remote monitoring and maintenance of a solar plant supervisory system. In this paper, authors created a prototype of the solar PV monitoring and optimization included a data acquisition system, control station, and supervisory monitoring at the plant level and Decision Support System (DSS) at the Central Management Station.

In 2015, Prakash et al. [8] described wireless wind turbine monitoring using Arduino. This paper described the implementation and design of a wireless monitoring system for turbines using the Arduino platform. There they employed an Arduino Uno-based WSN that measured and transmitted the various mechanical and electrical parameters of the turbine.

In 2015, Parikh et al. [9] described a solar panel condition monitoring system based on a wireless sensor network. They developed hardware and software discovery for fault detection and continuous monitoring system for solar panels in the distant areas.

In 2017, Kabalci et al. [3] presented the design and implementation studies of a remote monitoring system. The proposed modelling was improved in terms of smart measuring infrastructure based on voltage, current, and power metering.

In 2017, Jumaat et al. [10] described solar energy measurement using Arduino Uno. This project aimed to develop a measurement of solar energy using Arduino Uno board. In this paper, four parameters were measured: light intensity, temperature, current, and voltage.

In 2018, Madhubala et al. [11] described solar power based remote monitoring and control of industrial parameters using IoT. The main aim of this project was to develop a system for remote control and monitoring of important industrial parameters such as measurement of speed, gas, pressure, temperature, voltage, and current for prevention of human fatalities, diagnosis, automated range based access and two-way control, and extension of life of machinery using green technology in a friendly and secure manner using biometrics and the Internet.

In 2018, Parveen et al. [12] described an IoT-based solar tracking system for efficient power generation. The main goal of this paper was to design a very obvious tracker for solar panels and transmit the information through IoT. In this model, sensors of the sun's position was accomplished in two stages, primary and secondary.

In 2019, Vijayaragavan et al. [13] proposed a windmill monitoring system using IoT and WIFI. This paper described considerations of making use of WSN to scrutinize status within wind farms, taking into consideration the exact queries.

Finally, in 2019, Parveen et al. [14] described the simulation, fabrication, and monitoring of solar power plants using Arm7 and Proteus Software. It proposed an 
autonomous intellectual system. LDR and rain sensors were used to prevent the excess errors by solar cells during inappropriate situations. In this project, the modeling had to be done all the way to maintain high efficiency irrespective of environmental conditions.

However, this research work did not investigate the complex monitoring system of solar power plants of telecommunications facilities. Therefore, this research was implemented based on the energy consumption demands of telecommunications facilities.

\section{STATEMENT OF THE PROBLEM}

The ability to remotely monitor the production capacity of solar power stations and the status of batteries is important in the long-term maintenance of such power systems [15]. Various means of communication and IoT are used in remote monitoring systems of optional power sources [16-17]. Such means of communication are selected based on the principle of construction of the monitoring system.

For now, remote monitoring systems of existing solar energy sources is not an optimal solution for real-time monitoring of energy sources of telecommunications facilities. Existing systems have a number of technical limitations [8]. The main reasons for this are:

- The use of optical fiber technologies in remote monitoring systems is not always desirable, as telecommunications facilities are often located far away from the monitoring center, in deserts, mountains, forests, and plains.

- The monitoring system of energy sources of telecommunications facilities must promptly transmit data in real-time, implementation of a preventive system aimed at troubleshooting and diagnostics. This requires a secure and reliable connection to avoid serious failures and interruptions.

- It is important to keep the monitored parameters on the local monitoring center's server (database). This data collection allows us to study and predict failures and their timelines.

This work is focused on developing an optimal system for real-time remote monitoring of solar power sources of telecommunication facilities through wireless sensor networks. It aims at designing and simulating the system on the Proteus environment, with a focus to the technical constraints arising from the above.

\section{MAIN PART}

When developing a Solar Power Plant Remote Monitoring System, it is important to take into account all the parameters that apply to it. The main parameters for a solar power plant can be set as follows: solar panel power; the amount of solar radiation; environment temperature; environment humidity; voltage and current at controller output; controller temperature; voltage and current on the battery; battery temperature; accumulator charge; voltage and current at load; and required power of the load. They define the basic characteristics of the system [7], [9], [11-12]. The development of a monitoring system of all parameters for a solar power plant was initially designed as a block diagram.

\subsection{Structure of Monitoring System}

The solar power plant monitoring system has a complex construction. Figure 2 shows the overall structure of the monitoring system. It's built on a wireless sensor network (WSN) technology or ZigBee (IEEE Std 802.15.4) technology. 
ZigBee Networks consist of three types of devices (base stations): ZigBee Coordinator (Node Coordinator), ZigBee Router (Router Node), ZigBee End Device (End Node). ZigBee coordinator sets up, to forms and is a wireless network control center [1819].

ZigBee router expands network coverage built on this technology. It uses dynamic routing protocols to avoid various problems and obstacles (such as distance). It restores the route direction when a network load increases or when a device fails. ZigBee uses two types of routing protocols: the distance vector (AODV) and the link state (Cluster-Tree) [18].

The ZigBee End device can receive or transmit the message, but it does not have the ability to retransmit or route packets. The End device can be connected to a router or coordinator and does not support other devices.

The structural scheme of the system (Fig. 2) consists of a solar power plant, sensors, three types of ZigBee devices, a monitoring center, and Internet network interfaces. Solar power plant parameters are measured by sensors. One CDU and one ZigBee End device (End Node) are installed for each sensor that is used at the solar power plant. CDU detects sensor values and transmits them to the ZigBee End device as a message. The ZigBee End device transmits the message in packet form to the ZigBee router (Router Node). The ZigBee router detects the route direction of packets to the ZigBee coordinator (Coordinator Node) and transmits them on the optimum path. Each of the four ZigBee routers can transmit received packets to the ZigBee coordinator through the remaining routers, or one of the optional routers can transmit the packets directly to the coordinator [20]. The remaining routers can be intermediate routers. As this system consists of four routers, it can have between one, two, or three intermediate routes.

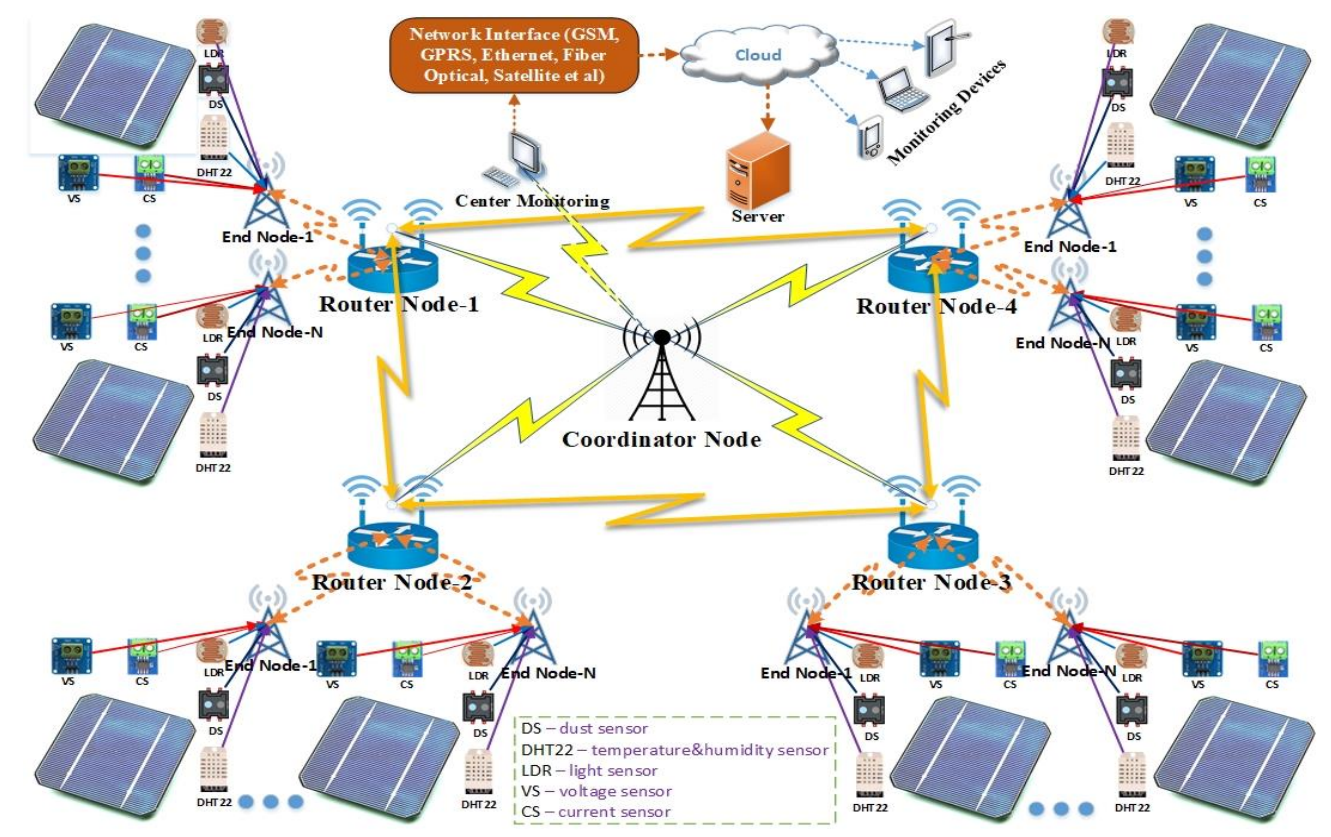

Fig. 2: Structure scheme of monitoring system based WSN.

The main task of the ZigBee coordinator in the system is to control the wireless network built on the sensors and transfer the data that are transmitting from the sensors to the monitoring center. In the monitoring center, the values measured by the sensors are controlled by administrator. At the same time, their information is transmitted to the server through Internet network interfaces (GSM, GPRS, Ethernet, Fiber optical network, 
Satellite et al.) [21]. The server saves hourly, daily, weekly, monthly, and yearly reports of values measured by sensors. This information can be tracked with authorization, using any devices that have access to the Internet network.

\subsection{Block Diagram of the Monitoring System of Solar Station}

The remote monitoring system of solar power sources through wireless sensor networks of the telecommunication facilities was conditionally divided into two parts: the data collection unit from the solar power station and the monitoring center (Fig. 3). The data collection unit from the solar power plant consists of the following blocks (Fig. 3a):

- solar panel;

- accumulator battery;

- voltage sensor;

- current sensor;

- humidity sensor;

- temperature sensor;

- light sensor;

- dust sensor;

- controller devices unit (Arduino UNO);

- wireless network module (ZigBee/Xbee);

- display;

- telecommunication objects (load).

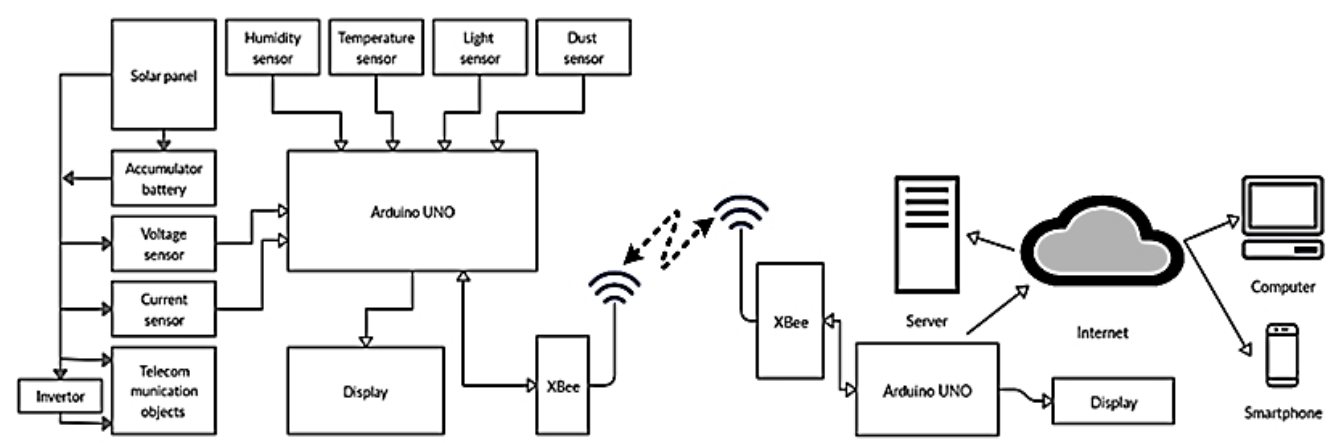

Fig. 3: Block diagram of the monitoring system of the solar station.

The monitoring center consists of the following blocks (Fig. 3.b):

- controller device unit (Arduino MEGA);

- wireless network module (ZigBee/Xbee);

- display;

- local server.

The monitoring center is also connected to the Internet, where the operator has access to the rights monitoring system assigned to it through any Internet-connected device [12]. 


\section{HARDWARE OF THE MONITORING SYSTEM OF SOLAR STATION}

This section provides basic information about the devices and modules used for designing and modeling on the Proteus software environment as described above [15].

\subsection{Solar Panel}

Solar panels are semiconductor devices that convert solar energy directly into electricity and are widely used as an alternative source of energy for telecommunications facilities. Depending on the number of photovoltaic converters in solar panels, they can produce unchanged currents of varying voltage and power, and may vary in size.

\subsection{Controller Device Units (Arduino UNO/MEGA)}

The Arduino Uno and the Arduino MEGA boards are taken as CDUs. The Arduino Uno was used to measure the parameters of the solar power supply from the control unit and transfer it to the central control unit. Arduino Uno is a board that is based on an open source microcontroller ATmega328P (Fig. 4.a) [22, 23].

Arduino MEGA was used as a centralized control unit. This control unit is designed to receive, process, and transmit signals from distributed solar panel control units of telecommunications facilities to the server. The Arduino MEGA board is integrated with the Atmega2560 microcontroller (Fig. 4.b) [24]. These boards are equipped with a set of digital and analogue input/output pins, which allow us to connect to various expansion boards and other circuits.

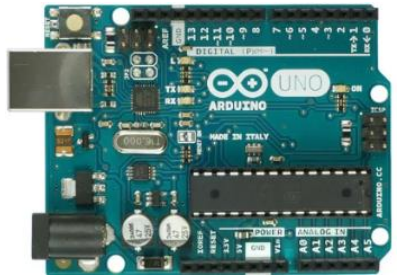

(a)

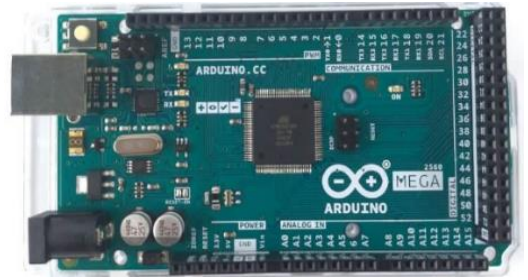

(b)

Fig. 4: CDUs: (a) Arduino Uno, (b) Arduino MEGA.

\subsection{Wireless Network Module (ZigBee/Xbee)}

ZigBee is a standard for high-level wireless communication protocols that support small, low-power digital transmitters based on IEEE 802.15.4 standard [25].

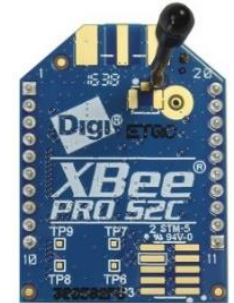

(a)

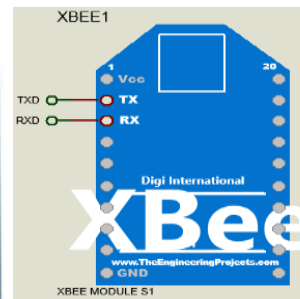

(b)

Fig. 5: ZigBee/Xbee wireless network module: a) real view of the module, (b) environmental view of the module in Proteus software.

\subsection{Display}


The LCD display is used to reflect the parameters being monitored. LCD displays are the most common type of TV and monitor screens, as well as phone and other device displays. We used a 128x64 OLED graphical display in this experimental model. Its real and Proteus software environmental views are illustrated in Fig. 6a and 6b. The display connects to the microcontroller unit through the I2C interface. This enables efficient use of the microcontroller ports [7], [10], [14].

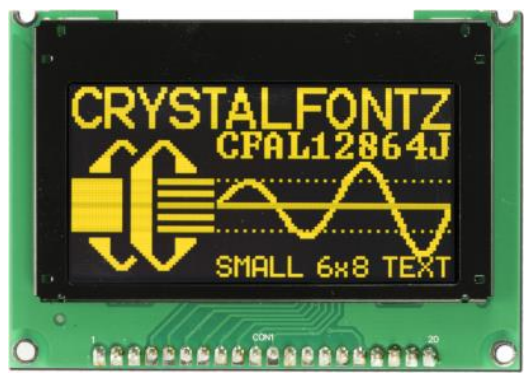

(a)

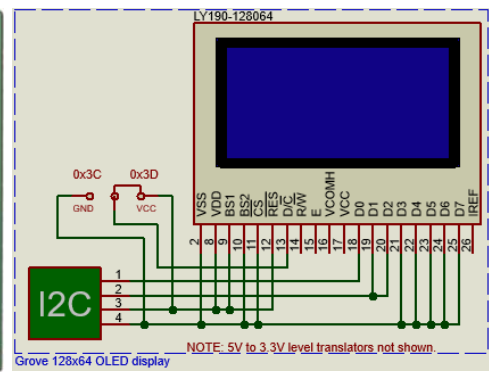

(b)

Fig. 6: 128x64 OLED graphical display: (a) real view of the module,

(b) environmental view of the module in Proteus software.

\subsection{Accumulator Battery}

A battery is a chemical power source; a reusable electrical driving force. Its main unique feature is the repetition of internal chemical processes, which allows it to accumulate energy and undergo multiple charge-recharge cycles for the autonomous energy supply of various electrical appliances and equipment [26]. In the model, four $12 \mathrm{~V}$ batteries (48 V total) were used (Fig. $7 \mathrm{~b}$ ). But in this case, there is one problem: it is impossible to show the battery charging or discharging during the ANIMATING time of the Proteus environment in the model. Therefore, an RV3 pot resistor was installed to show this condition. By changing this resistance, the battery voltage is increased or decreased which increases or decreases its charge. A voltage sensor consisting of R6 and $\mathrm{R} 7$ resistors was used to detect the voltage in the battery [22]

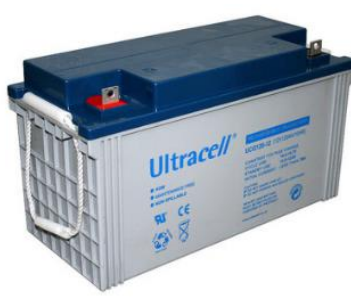

(a)

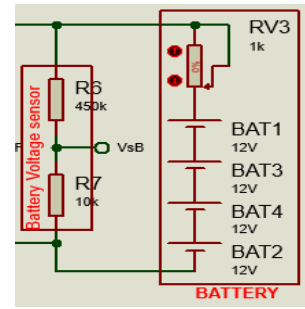

(b)

Fig. 7: Accumulator battery: (a) real view of the module, (b) environmental view of the module in Proteus software.

\subsection{Temperature and Humidity Sensor}

The DHT22 series sensor was used to measure the temperature and humidity of the area where the solar panel was installed (Fig. 8). The DHT22 sensor is a well-established electronic temperature and humidity sensor that connects the microcontroller and the DHT22 sensor through a single data-exchange line. The single-line data exchange time is $5 \mathrm{~ms}$, with the measured temperature and humidity data being transmitted simultaneously [11], [30]. 


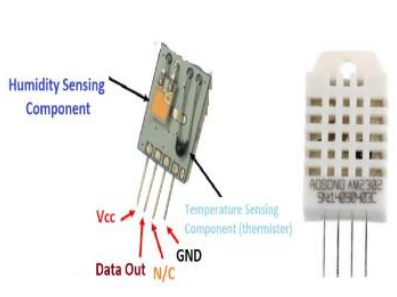

a)

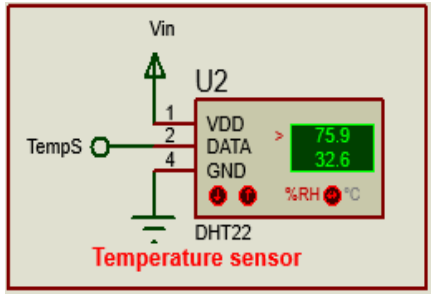

b)

Fig. 8. Temperature and humidity sensor: a) real view of the module b) environmental view of the module in Proteus software.

\subsection{Current Sensor}

The AC power sensor is a device used to measure and control alternating current, direct current, and pulse current. Current sensors are widely used in electrical engineering to create contrariwise communication systems. There are various types of current sensors such as resistive current sensors, current transformers, and Hall effect sensors. Hall effect sensors can measure and control DC current, AC current, and pulse current. In addition, they have reliable electrical insulation, stand out with a wide range of frequencies, and do not emit heat [5], [22], [24], [27-28].

Presently, there are many sensors that detect current. They differ from each other by the power measurement limit. Because the system we are building is high-power, we used ACS755XCB-050 as a 50 A current sensor [3], [7-8], [12]. Its real and virtual views are shown in Fig. 9.

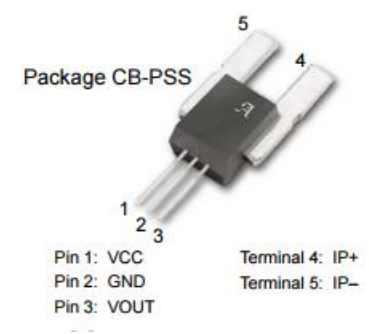

(a)

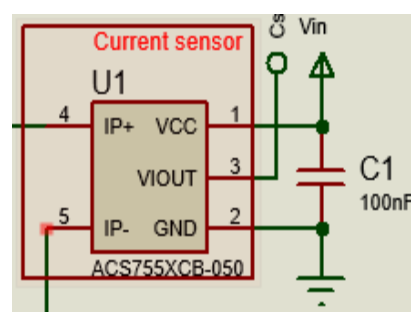

(b)

Fig. 9: ACS755XCB-050 current sensor: (a) real view of the module,

(b) environmental view of the module in Proteus software.

\subsection{Voltage Sensor}

The voltage sensor is a module that measures the voltage in the network. There are several types: voltage sensors of transformers, resistors, capacitors and other types. The most common type of voltage sensor is made with two resistors. It has a very simple structure. The two resistors are connected in series (such as R4/R5 and R6/R7) and their loose ends are connected to the power supply (as shown in Fig. 10). At the same time, a high voltage is distributed over these resistors. As a result, a voltage of less than $5 \mathrm{~V}$ is generated on the point where the two resistors connected. To convert high voltage to low voltage, the Atmega microcontroller control unit receives a voltage signal of up to $5 \mathrm{~V}$. From their common endpoint, a small voltage signal is transmitted to the control unit of the Arduino board. The small voltage signal is converted to numerically accurate value using a special formula in the program [5], [22], [24], [27], [29]. 


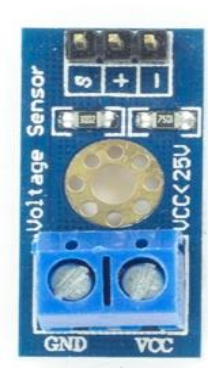

(a)

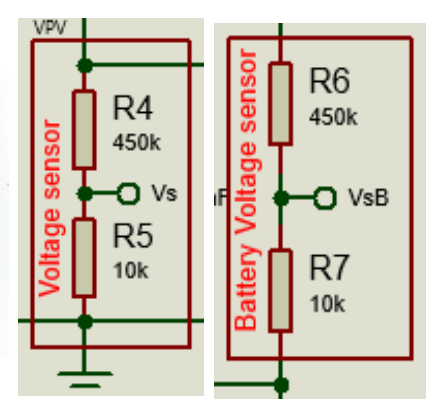

(b)

Fig. 10: Voltage sensor: (a) real view of the module,

(b) environmental view of the module in Proteus software.

The imitation model uses two voltage sensors. One of them determines the amount of voltage in the common mains and the other determines the amount of voltage in the battery. The amount of charge on the battery is calculated with the second sensor.

\subsection{Light Sensor}

The light sensor is a device for measuring the level of ambient light. In the model, light sensors are used to monitor the degree of illumination of the telecommunications facilities in the area where solar energy sources are located, to determine whether it is sunny or cloudy and whether the area's illumination is sufficient for energy production. The range of light sensors is formed at different intervals (luxe). They can be adjusted depending on the location and conditions of installation [7], [9-10]. A photoresistor was used to detect the illumination in this system (Fig. 11). The photoresistor resistance varies linearly as the ambient light changes. In this case, at the same time as the amount of light that comes on the photoresistor surface, its resistance decreases linearly, and with the decrease in the amount of light, its resistance increases. Therefore, the amount of ambient light is measured depending on the photoresistor resistance [22].

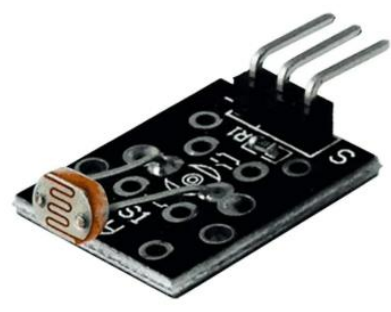

(a)

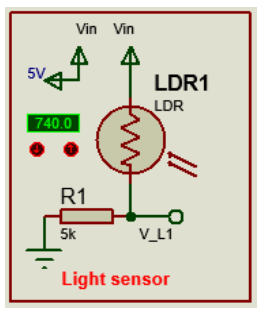

(b)

Fig. 11. Light sensor: (a) real view of the module, (b) environmental view of the module in Proteus software.

\subsection{Dusting Sensor}

The dust sensor can measure the dust value by transmitting a signal between 4 and 20 $\mathrm{mA}$, or report that the dust level exceeds the set values. Many dust sensors operate on the principle of quantum particle measurement and detect high-resolution particles larger than one micron. These particles include cigarette smoke, household dust, spores, mold and more. Typically, sensors such as SM-PWM-01C, GP2Y1010AU0F are used to determine the level of dust. These sensors determine the concentration of dust in the air using an optical sensitivity method. The infrared light-emitting diode (IR LED) and photo-sensor 
(Photo Transistor) are used as optical sensors. The photosensor receives infrared light passing through dust particles [9].

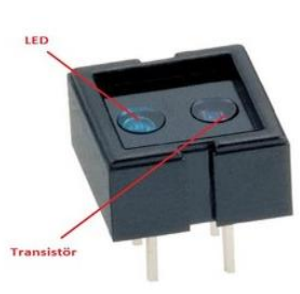

(a)

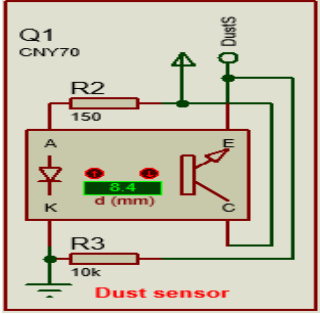

(b)

Fig. 12: Dusting sensor: (a) real view of the module,

(b) environmental view of the module in Proteus software.

The CNY70 element was used as a dust sensor in the Proteus software environment (Fig. 12). In fact, the CNY70 element is used for other purposes. However, experience has shown that this element can also be used as a dust sensor in real conditions, and that is appropriate for our experimental sample necessitating only some minor experiments.

\subsection{Virtual Terminal}

In the modeling, we used the additional capabilities of the Proteus software environment to monitor and analyze transmitting data in real-time.

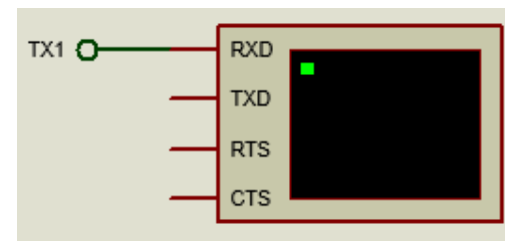

(a)

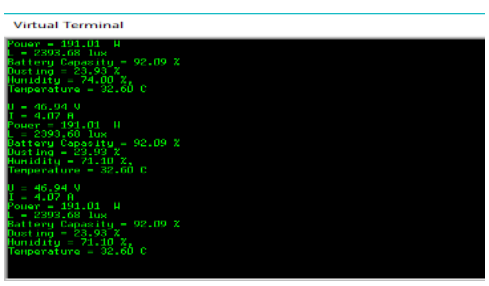

(b)

Fig. 13: Virtual terminal: (a) method of connection to the system, (b) appearance of values in the simulation.

One of them is the Virtual Terminal. It communicates with Arduino through the UART interface [13]. It is possible to print optional information in the virtual terminal based on the parameters entered in the program. In this model, the measured constants shown in Fig. 13 can be monitored in real-time.

\section{SOFTWARE ALGORITHM OF THE MONITORING SYSTEM OF SOLAR STATION}

The solar power station monitoring system has been modelled in two parts: solar power station management and its measurement system and monitoring center. They can be viewed as a distributed system. In other words, these two systems are at a certain distance from each other and have related and unrelated control processes [4]. Therefore, a separate software was written for each system model in the Arduino IDE environment. Their algorithm is illustrated in Fig. 14 as a block diagram. 


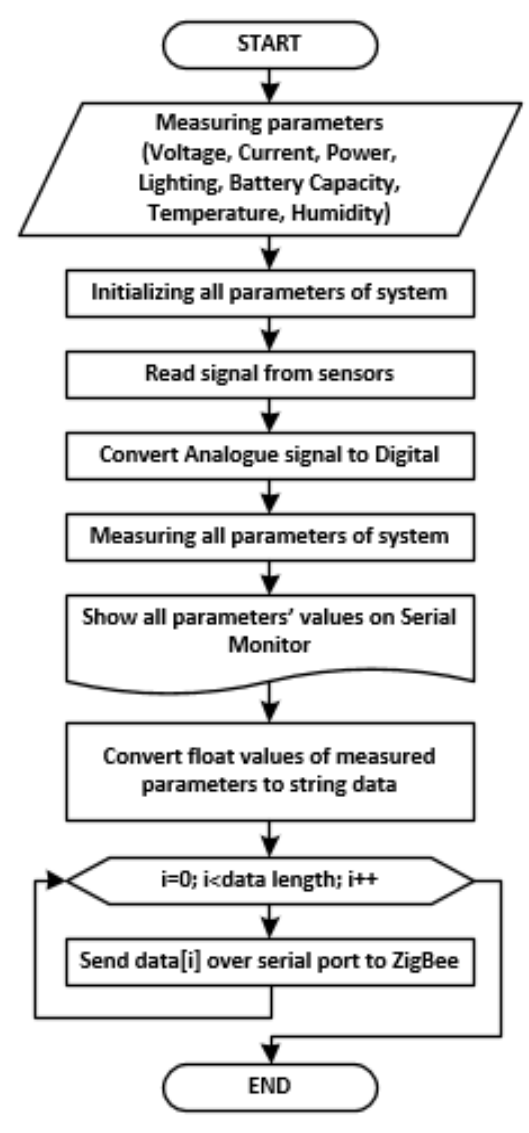

(a)

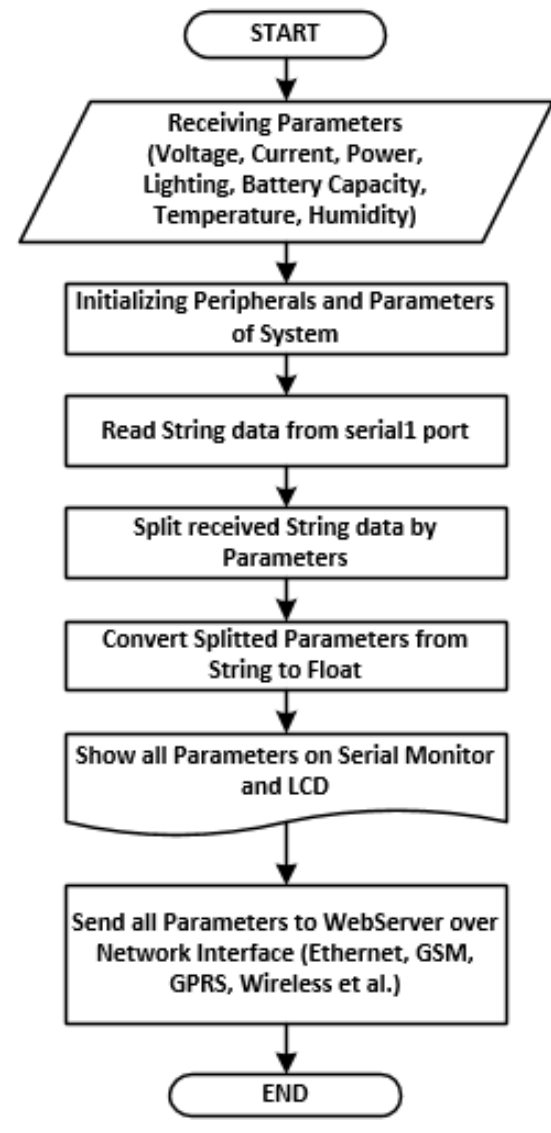

(b)

Fig. 14: Software algorithm for monitoring system: (a) software algorithm for transmission part, (b) software algorithm for receiving part.

Figure 14a illustrates the solar power station management and its algorithm for the measuring software system. As shown in this algorithm, the incoming signals from the sensors located in the object are converted to digital and the value is determined. All defined parameters are first displayed in the Serial Monitor [22].

At the same time, the values of this parameter are passed through the serial ports to the XBee wireless network module. However, because the measured values are multiple and the value type is float, they cannot be written directly to the serial port. Otherwise, the values may be mixed and the monitoring center will receive error values. Therefore, the value of each parameter (value type - float) is initially converted to a specified amount or byte sequence (Value type - String). Then, in order to distinguish each parameter from the other, the characters are appended to the front of the values and formed in the form of a common data package. Each symbol of the formed data is passed through serial ports to the XBee wireless network module. The data is transmitted to the monitoring center using a wireless network module.

Figure 14b illustrates the algorithm of the management system of the solar power station's monitoring center. In this case, after the system is fully loaded, the serial port determines the data flow or byte sequence (value type - String) from the XBee wireless network module. Then each character in this information is scanned and the value corresponding to the character is divided by the measured parameters. The value of each allocated parameter is initially specified as a String type of value. On such a value, it is impossible to perform mathematical calculations and display on the screen thus, they are 
converted to float type of values (type of value - float). Defined parameters are displayed on the Serial Monitor and LCD. At the same time, these values are transmitted to Web Server using Internet network interfaces.

\section{DESIGNED STRUCTURES OF THE MONITORING SYSTEM}

The structure of the power monitoring system of any facility consists of three parts: the measuring part, the server part, and the web page. Specific sensors (such as current, voltage, etc.) are installed in the measurement unit for energy sources and consumer loads. These sensors are connected to the control unit, which is a small computing system.

The sensors detect changes in the object and transmit the signal to the control unit as voltage or current. The control unit converts the voltage or current signal into digital form and transmits it via the wireless network to the central control unit (or Monitoring Center). There may be more than one such system. The information transferred from them is consolidated in the central control unit (Monitoring Center) and transmitted via the Internet to the server. At the same time, it is possible to monitor real-time values from sensors using a web browser [3], [11].

The process of designing remote monitoring of solar power sources of telecommunications facilities in the Proteus software environment was carried out in three stages:

- Equipping the solar power station with sensors and IoT technology;

- Equipping the monitoring center with IoT technology

- Creating a website for monitoring.

Typically, this system is designed to remotely monitor solar power stations located in different areas. As an example, in this experiment, we implemented a monitoring system on only one solar power plant in a virtual environment. But our idea is to monitor all the power plants in the designated area. There may be more than 100 such solar power stations.

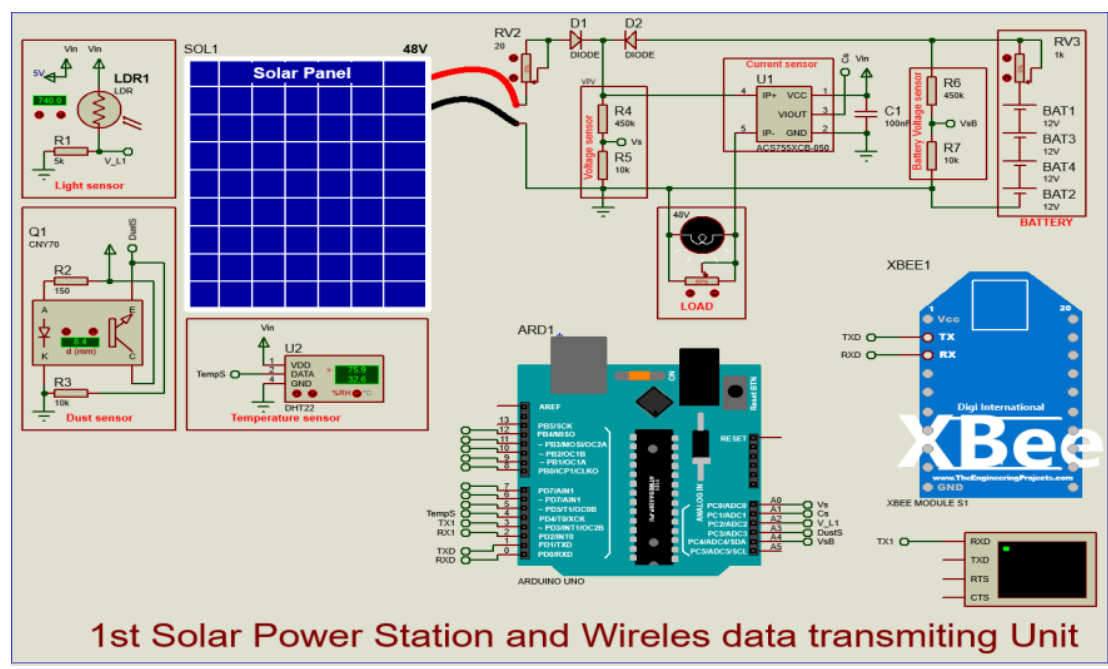

Fig. 15: Solar power plant equipped with IoT technology.

Figure 15 shows the first step of the system we designed in the virtual environment. Several sensors are used for the area where solar panels are located and telecommunications facilities: light sensors, dust sensors, temperature and humidity 
sensors, voltage sensors, and current sensors. The characteristics of these sensors are mentioned above. They usually serve to determine the condition of the solar panel's installed location (such as the temperature of the solar panel, dust on the surface, and ambient humidity), the amount of energy the solar panel produces, the amount of battery charge, and energy consumed by telecommunications facilities [2], [22-24]. Defined parameters are transmitted to the monitoring center using the ZigBee/Xbee wireless network module.

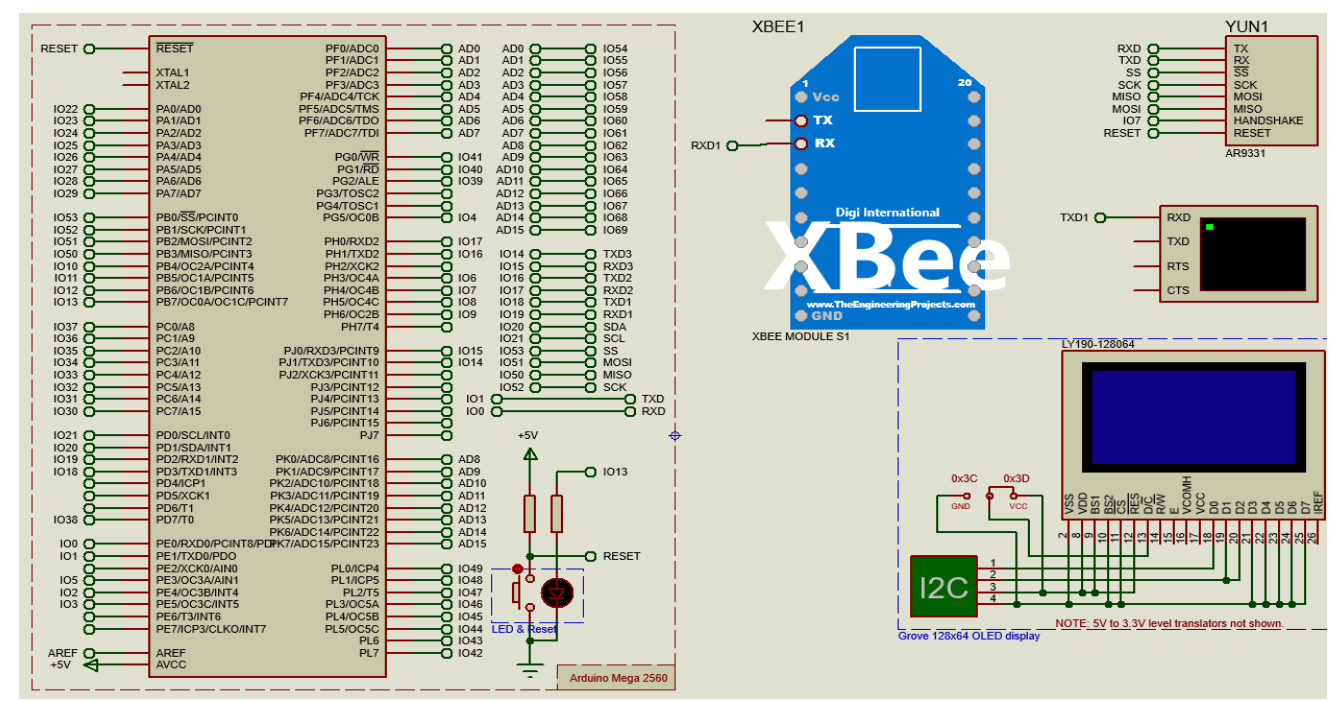

Fig. 16: Monitoring center equipped with IoT technology.

In the next section, the Monitoring Center is designed to monitor and analyze the parameters measured at solar power plants (Fig. 16). The monitoring center is equipped with Arduino MEGA, virtual terminal, ZigBee/Xbee wireless network module, LCD display, as well as Internet network module (may include YUN WIFI \& Ethernet module, as well as GSM, Ethernet, WIFI). The monitoring center receives the parameters measured and transmitted at the solar power plant using the ZigBee/Xbee wireless network module. The received data is displayed using a virtual terminal and LCD display. Simultaneously, these parameters are passed to the webserver. The measured parameters are stored in the webserver memory.

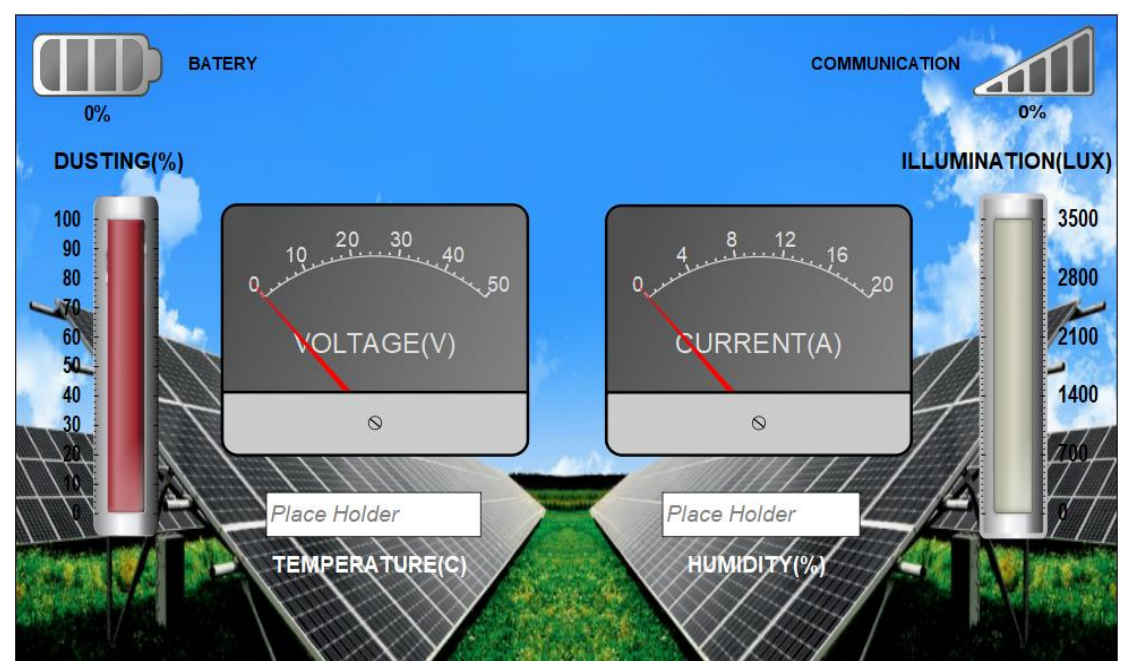

Fig. 17: Web page view for the monitoring system. 
It is well known that the monitoring system requires a system of remote control, management and evaluation of the distributed system parameters to stay at a discretionary distance. A simple web page was created to fulfil the tasks set out in the third stage of monitoring system modelling (Fig. 17).

The webpage can be referenced by typing a web address in any web browser. As a result, a web browser will display the page shown in Fig. 17. On this page, the values of the solar power plants' measured parameters (solar panel dust, voltage, current, battery charge, ambient light, temperature, humidity) are presented in various graphical images and figures. Every change can be seen in real-time using this webpage. This allows us to monitor system performance, quickly identify problems, and use optimal solutions to address them, to evaluate and improve the system's performance.

\section{SIMULATION PROCESS OF THE MODEL}

The solar power station monitoring system of telecommunications facilities modelled in the Proteus software environment is a virtual system. It is required to create a wireless sensor network between the ZigBee/Xbee network modules to transfer from the station to the monitoring center. The exchange of data between wireless sensor networks is carried out by electromagnetic waves in the environment [31-32]. However, the simulation environment is embedded in a single PC software that cannot generate signals using electromagnetic waves. The Xbee network module in the Proteus software environment (Fig. 5b) is built on the RS232 serial communication interface. Information exchange between RS232 serial communication interfaces is provided through a physical communication port (COM Port - Communication Port). This means that a virtual communication port should be created on the PC to provide communication between the Xbee network modules in the Proteus software environment. A lot of software is available on the PC to develop virtual communication ports. For this model, VSPE (Virtual Serial Port Emulator) software was used to create a virtual COM port on the PC, and virtual COM2 and COM3 ports were created. They are configured for the Xbee network module in the Proteus software environment (Fig. 18).

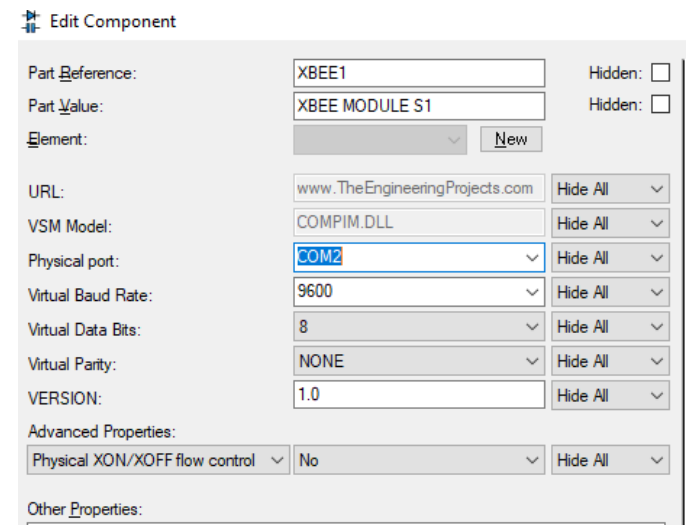

(a)

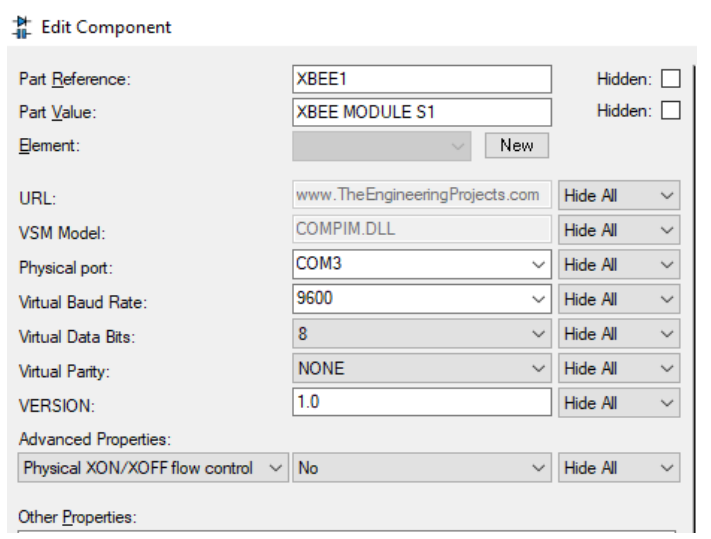

(b)

Fig. 18: Xbee network module configuration window in Proteus software environment: (a) for the transmitter Xbee network module at the station, (b) for the receiving Xbee network module at the monitoring center.

As mentioned above, data received by the monitoring center is transmitted to the Internet using the YUN WIFI \& Ethernet network interface. To view the transmitted 
values in a PC web browser, you need to configure the local host port number for the YUN WIFI \& Ethernet network interface. In this model, the 8181 localhost port number is configured for the YUN WIFI \& Ethernet network interface (Fig. 19).

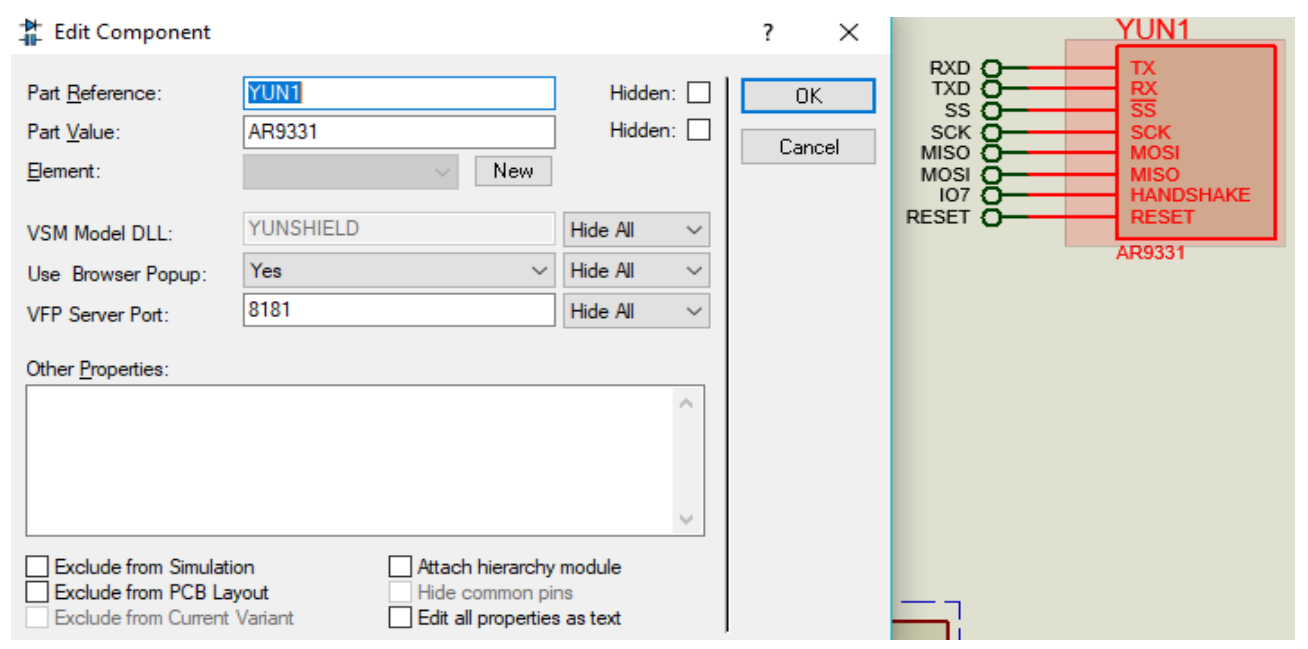

Fig. 19: Configuration window the YUN WIFI \& Ethernet network interface in Proteus software environment.

After the settings have been fully set up, by simultaneously launching the simulation models of the solar power plant wireless transmission system and the monitoring center, the simulation results can be verified, the values of sensors located on the solar station (Fig. 20a) can be changed, and the results can be monitored on the LCD display and virtual terminal located in the monitoring center (Fig. 20b). Also, the monitoring center transmits the measured values to the webserver using the Internet network interface. Figure 20 shows the simulation result of the monitoring system. The signal view of transmitted and received information is displayed through the digital oscilloscope.

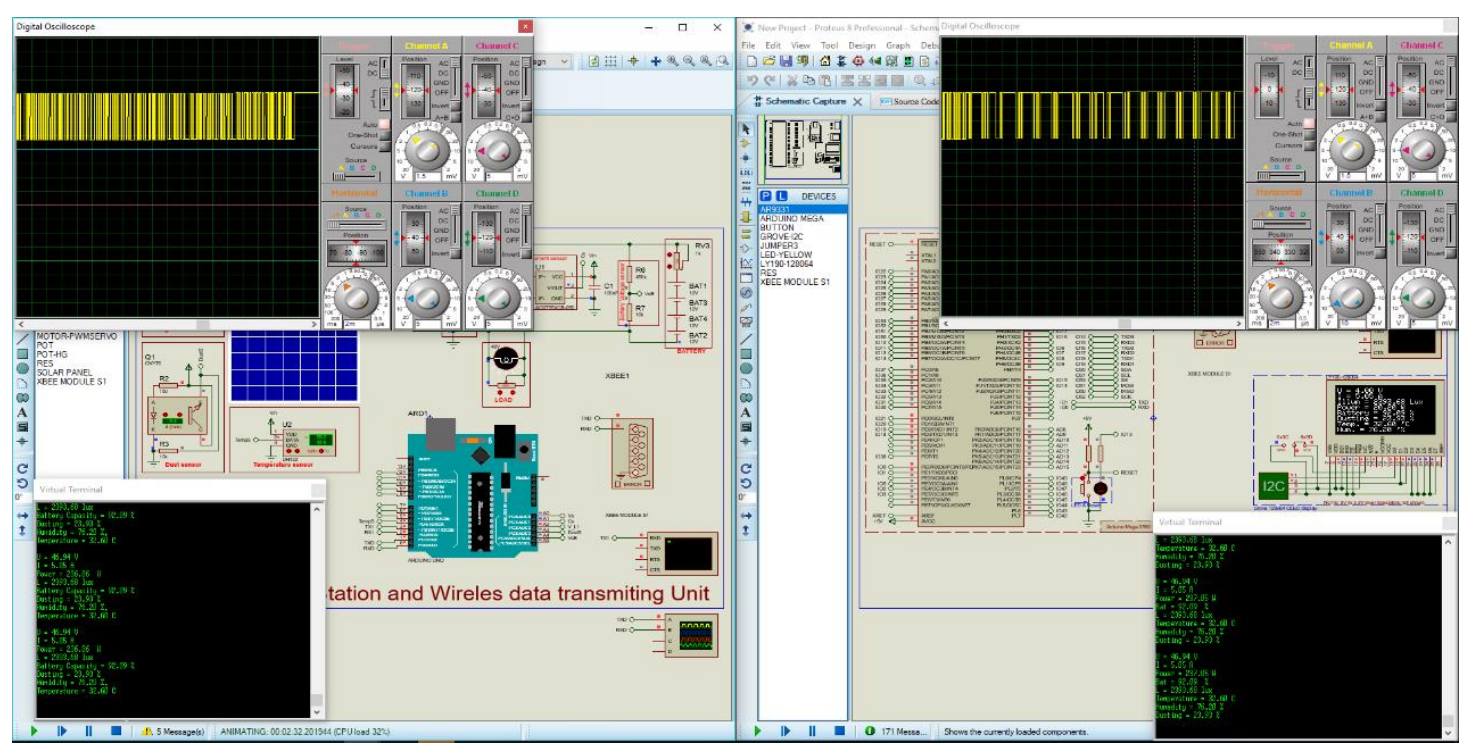

(a)

(b)

Fig. 20: The window of the simulation process with transmitting (a) and receiving, (b) data. 


\section{RESULTS}

The results of the system model simulation process were usually analyzed using the Virtual Terminal and a digital oscilloscope. The Virtual Terminal and Digital Oscilloscope are connected to the signal channels transmitted by the solar power station to the Xbee network module and received through the Xbee network module located in the monitoring center, as well as the Internet wireless interface (YUN WIFI \& Ethernet). The initial check was performed for transmitted and received signals, and the results are illustrated in Fig. 21 and 22. Figure 21a belongs to the transmitting values and Fig. 21b belongs to the receiving values. In this Fig., the values transmitted by the station and received by the monitoring center are the same. This means that the measured values are passed and received through the Xbee network module without any errors.

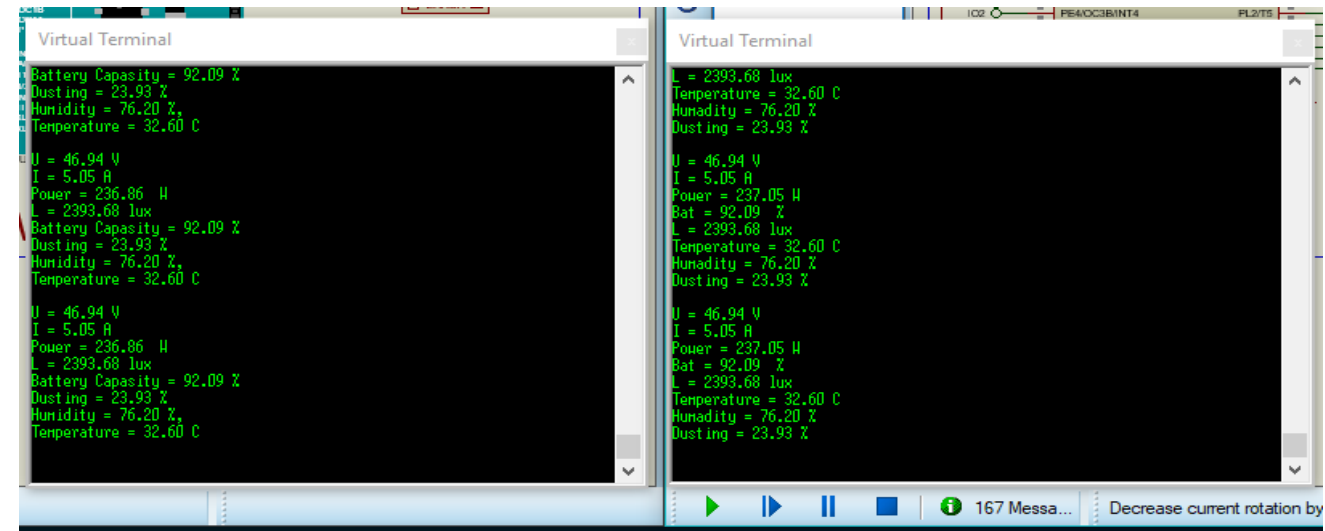

(a)

(b)

Fig. 2: The view window of values transmitted and received by the Xbee network module during the simulation in the Virtual Terminal.

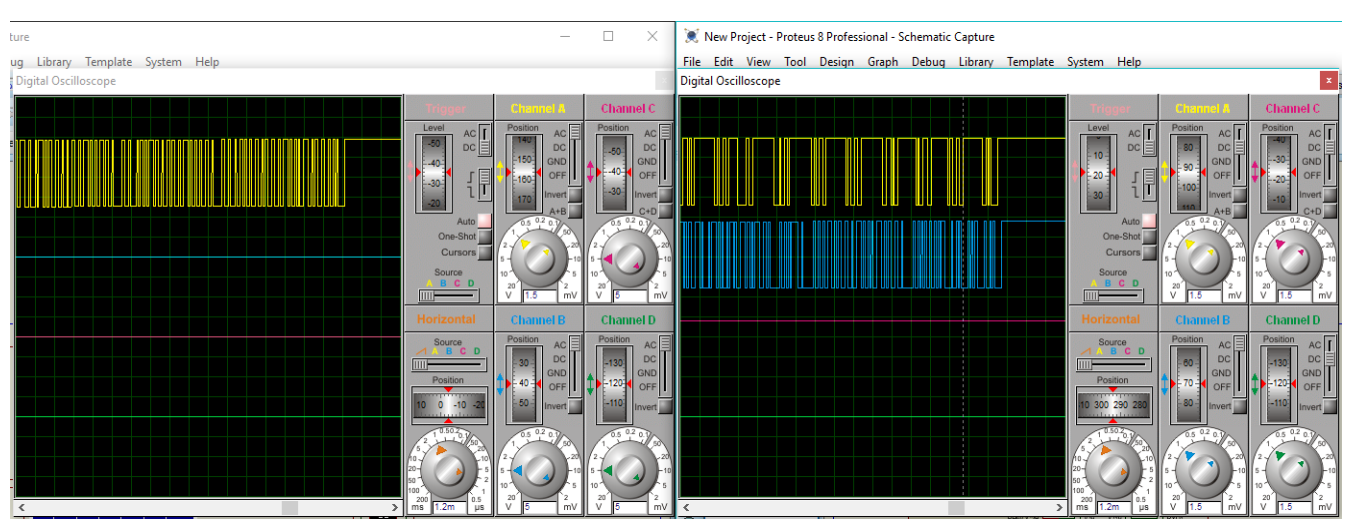

a) b)

Fig. 22: The electrical signal graph of the transmitting and receiving values by the Xbee network module during the simulation.

Using the Digital Oscilloscope, the electrical signal view of the values shown above gave the following results (Fig. 22). All channels (channels A, B, C, D) of the Digital Oscilloscope are set to the same setting to compare the signal status. In the graph, the yellow line represents the signal being transmitted and received. In this case, the electrical signal of the transmitted data differs from that of the received signal. This is because additional information is being added to ensure the reliability and accuracy of the transmitted data. The blue line signal graph in Fig. 22b represents an unexpectedly 
generated signal. This can be seen as a signal that the information has been received. As you can see from these pictures (Fig. 21 and 22), the parameters measured at the solar power station and reach the monitoring center in the form of data using a wireless sensor network.

The next step was to analyze the signal graphs transmitted and received by the monitoring center to the webserver (Fig. 23b). As you know, web servers are based on the client-server architecture. The client first sends a request to the server, and the webserver responds to the request based on the received request. Therefore, this image also shows the transmitting information (or request) signal by the monitoring center and the receiving information (or confirmation response) signal from the server. In this case, the transmitted signal graphic to the webserver is a red line, and the received signal graphic is green.

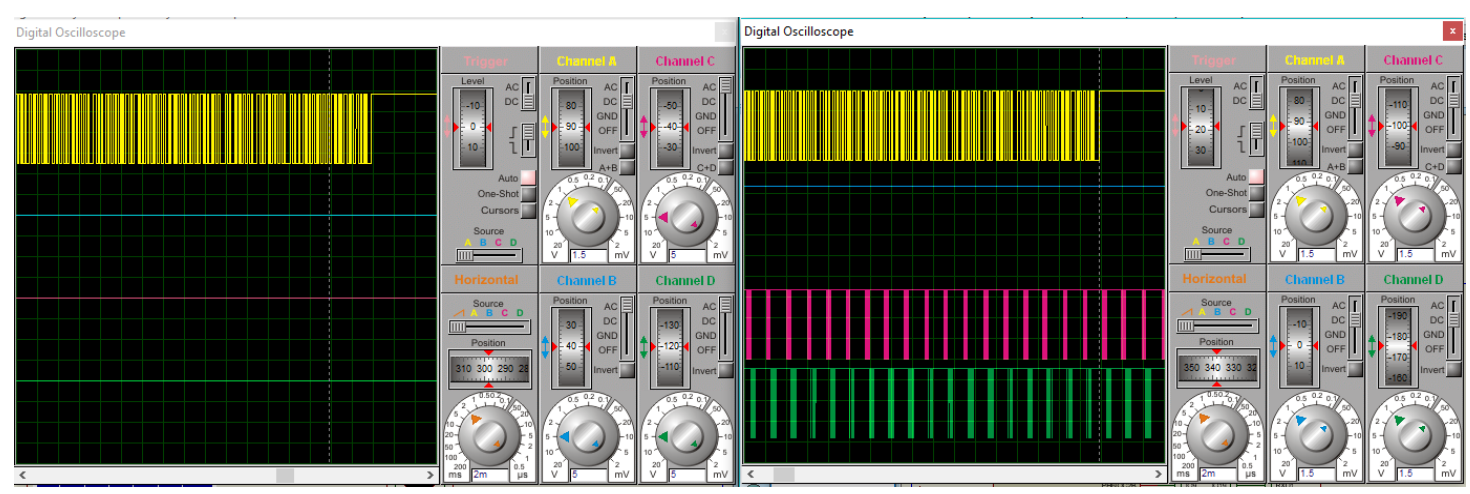

(a)

(b)

Fig. 23: The electrical signal graphics of data transmitted and received by the Xbee network module (a) and the Internet network module (b) during the simulation.

In this figure, the graph shows the transmitted and received signals appearing at the same time. We place them on top of each other to see the difference between the transmitted and received signals (Fig. 24), the difference is obvious.

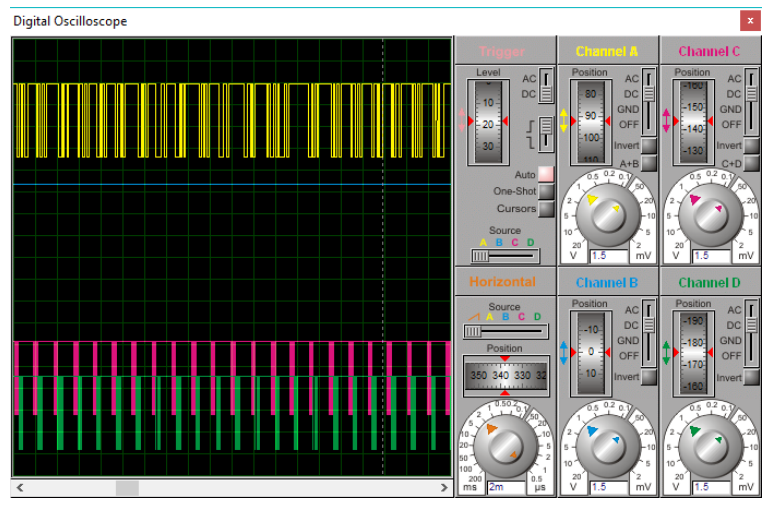

Fig. 24: Comparative electrical signal graph of data transmitted and received by the network module in the simulation process.

We can see the simulation results of the telecommunications facilities solar power station monitoring system model in any web browser installed on PCs or smartphones. The result of the simulated system was verified using a Microsoft Edge web browser installed on the PC (Fig. 22). To view the results, open the web browser and enter "localhost: 8181". As a result, the web page shown in Fig. 25 will open. With this web page, the system status can be monitored in real-time 


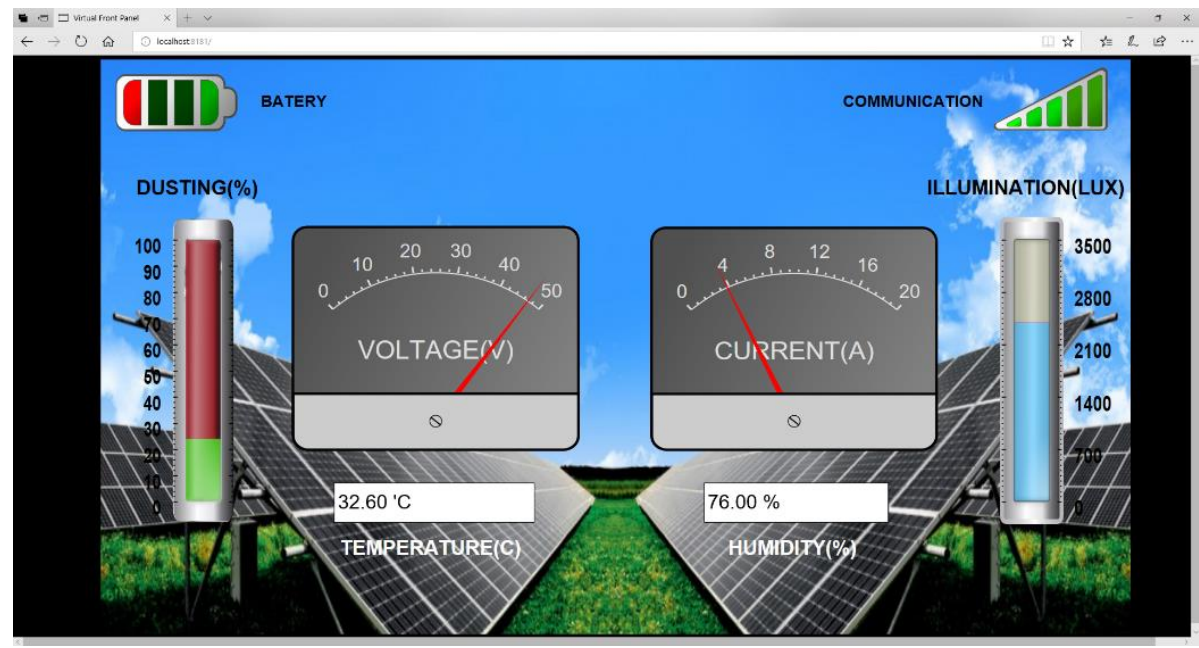

Fig. 25: Web page view of solar power station monitoring system.

\section{CONCLUSION}

Today, the increasing demand for renewable energy sources has led to the development of research and improved the efficiency of such systems used in various facilities. In particular, the use of solar power stations for telecommunications facilities is a crucial factor in energy conservation. Therefore, the design of this system was developed and modelled. A software product for this system has been created. There was research on all parameters of the solar power plant. We can be watching when these settings were changed. The monitoring center and webpage settings were changed. In this case, when the optional parameters of the solar power station were changed, the monitoring center and website were updated at the same time. The value has been changed to replace the previous one. This system is a crucial factor for the accurate and reliable operation of the system.

\section{REFERENCES}

[1] Pansare J. Sonavane SS. (2016) Efficient Energy Management in Smart Grids based on Raspberry Pi \& Web of Things. International Journal of Science Technology \& Engineering, 2(12).

[2] Tanwar S, Tyagi S, Kumar S. (2018) The role of Internet of things and smart grid for the development of a smart city. Intelligent Communication and Computational Technologies: January 2018; pp 23-33. https://doi.org/10.1007/978-981-10-5523-2_3

[3] Kabalci E, Kabalci Y. (2017) Remote Monitoring System Design for Photovoltaic Panels. The 10th International Symposium on Advanced Topics in Electrical Engineering: 23-25 March 2017, Bucharest, Romania.

[4] Chunming W, Liang Ch. (2012) The Monitoring System for the Wind Power Generation Based on the Wireless Sensor Network. International Conference on Future Electrical Power and Energy Systems: 2012; Hainan University, China.

[5] Siddikov IX, Sattarov KhA., Khujamatov KhE. (2017) Modeling of the Transformation Elements of Power Sources Control. International Conference on Information Science and Communications Technologies: 2-4 November 2019; Tashkent, Uzbekistan.

[6] Muradova AA, Khujamatov H. (2019) Results of Calculations of Parameters of Reliability of Restored Devices of the Multiservice Communication Network. International Conference on Information Science and Communications Technologies: 2-4 November 2019; Tashkent, Uzbekistan. 
[7] Nagalakshmi R, Babu BK, Prashanth D. (2014) Design and Development of a Remote Monitoring and Maintenance of Solar Plant Supervisory System. International Journal of Engineering and Computer Science, 3(12).

[8] Prakash S, Vijayaragavan SP. (2015) Wireless Wind Turbine Monitoring Using Arduino. International Journal of Advanced Research in Electrical, Electronics and Instrumentation Engineering, 4(7).

[9] Parikh A, Pathan F, Rathod B, Shah S. (2015) Solar Panel Condition Monitoring System based on Wireless Sensor Network. International Journal of Science, Engineering and Technology Research, 4(12).

[10] Jumaat SA, Othman MH. (2017) Solar Energy Measurement Using Arduino. MATEC Web of Conferences 150: 2017, MUCET.

[11] Madhubala S, Nachammai R, Nandhini I, Preethisha AM, Paulin JJ. (2018) Solar power based remote monitoring and control of industrial parameters using IoT. International Research Journal of Engineering and Technology, 5(3).

[12] Parveen R, Mohammed AM, Ravinder K. (2018) IoT based solar tracking system for efficient power generation. International Journal of Research and Analytical Reviews, 5(4).

[13] Vijayaragavan SP, Karthik B, Sriram M. (2019) Wind Mill Monitoring System using IOT and WI-FI. International Journal of Recent Technology and Engineering, 8(1).

[14] Farzhana PM, Neelavathy R, Reshma SB, Saravanakumar U. (2019) Simulation, Fabrication and Monitoring of a Solar Power Plants using Arm7 and Proteus Software. International Journal of Engineering Science and Computing, 9(5).

[15] Davronbekov DA, Matyokubov UK. (2020) The Impact of Mobile Communication Power Supply Systems on Communication Reliability and Viability and Their Solutions. International Journal of Advanced Science and Technology, 29(5): 374-385.

[16] Davronbekov DA, Aliev UT, Isroilov JD. (2017) Using the energy of electromagnetic radiation as a source of power. International Conference on Information Science and Communications Technologies, Applications, Trends and Opportunities: 2-4 November 2016; Tashkent, Uzbekistan https://doi.org/10.1109/ICISCT.2017.8188565

[17] Pulatov ShU, Aliev UT, Isroilov JD. (2017) Energy harvesters wireless charging technology. International Conference on Information Science and Communications Technologies, Applications, Trends and Opportunities: 2-4 November 2017; Tashkent, Uzbekistan. https://doi.org/10.1109/ICISCT.2017.8188566

[18] IEEE Computer Society. (2015) IEEE Standard for Low - Rate Wireless Networks. IEEE Std 802.15.4TM-2015.

[19] Khujamatov Kh, Khaleel A, Reypnazarov E, Khasanov D. (2020) Markov Chain Based Modeling Bandwith States of the Wireless Sensor Networks of Monitoring System. International Journal of Advanced Science and Technology, 29(4): 4889-4903. http://sersc.org/journals/index.php/IJAST/article/view/24920

[20] Khujamatov Kh, Khasanov D, Reypnazarov E, Akhmedov N. (2020) Networking and Computing in Internet of Things and Cyber-Physical Systems. International Conference Application of Information and Communication Technologies: 7-9 October 2020; Tashkent, Uzbekistan.

[21] Isroilov JD. (2016) Linearization spectral characteristics through passage by means of akusto-optical reconstructed filters. International Conference on Information Science and Communications Technologies, Applications, Trends and Opportunities: 2-4 November 2016; Tashkent, Uzbekistan. https://doi.org/10.1109/ICISCT.2016.7777386

[22] Khujamatov Kh.E., Khasanov D.T., Reypnazarov E.N. (2019) Modeling and Research of Automatic Sun Tracking System on the bases of IoT and Arduino UNO. International Conference on Information Science and Communications Technologies: 4-6 November 2019; Tashkent, Uzbekistan.

[23] Davronbekov DA. (2016) Features measurement parameters and control functioning of integrated chips. International Conference on Information Science and Communications Technologies: 2-4 November 2016; Tashkent, Uzbekistan. 
[24] Khujamatov Kh.E., Khasanov D.T., Reypnazarov E.N. (2019) Research and Modelling Adaptive Management of Hybrid Power Supply Systems for Object Telecommunications based on IoT. International Conference on Information Science and Communications Technologies: 4-6 November 2019; Tashkent, Uzbekistan.

[25] Davronbekov DA, Aliev UT, Isroilov JD, Alimdjanov XF. (2019) Power providing methods for wireless sensor. International Conference on Information Science and Communications Technologies: 4-6 November 2019; Tashkent, Uzbekistan. https://doi.org/10.1109/ICISCT47635.2019.9011850

[26] Skyllas-Kazacos M, Menictas C. (2013) Electricity Transmission, Distribution and Storage Systems. Woodhead Publishing Series in Energy.

[27] Siddikov I, Sattarov Kh, Khujamatov Kh, Dexkhonov O, Agzamova M. (2018) Modeling of Magnet Circuits of Electromagnetic Transducers of the Three-Phases Current. International Scientific-Technical Conference on Actual Problems of Electronics Instrument Engineering: 2-6 October; 2018; Novosibirsk; pp 419-422.

[28] Siddikov I, Sattarov Kh, Khujamatov H. (2016) Research of the Influence of Nonlinear Primary Magnetization Curves of Magnetic Circuits of Electromagnetic Transducers of the Three-phases Current. Universal Journal of Electrical and Electronic Engineering. Horizon Research Publishing Corporation, 4(1): 29-32

[29] Siddikov I, Sattarov Kh, Khujamatov H. (2018) Modeling and research circuits of intelligent sensors and measurement systems with distributed parameters and values. Chemical technology control and management. International Scientific and Technical Journal, 4(5): 50-55.

[30] Aosong Electronics Co., Ltd. Digital-output relative humidity \& temperature sensor/module DHT22 (also named as AM2302), DHT22 datasheet.

[31] Arsheen S, Wahid A, Khaleel A, Khujamatov Kh. (2020) Flying Ad hoc Network Expedited by DTN Scenario: Reliable and Cost-effective MAC Protocols Perspective. International Conference Application of Information and Communication Technologies: 7-9 October 2020; Tashkent, Uzbekistan.

[32] Siddikov IKh, Sattarov KhA, Khujamatov KhE, Dekhkonov OR. (2016) Modeling the processes in magnetic circuits of electromagnetic transducers. International Conference on Information Science and Communications Technologies: 2-4 November 2016; Tashkent, Uzbekistan. 